\title{
Association of changes in red meat consumption with total and cause specific mortality among US women and men: two prospective cohort studies
}

\author{
Yan Zheng, ${ }^{1,2,3}$ Yanping Li, ${ }^{3}$ Ambika Satija, ${ }^{3}$ An Pan, ${ }^{4}$ Mercedes Sotos-Prieto,,${ }^{3,5,6,7}$ Eric Rimm, ${ }^{3,8,9}$ \\ Walter C Willett, ${ }^{3,8,9}$ Frank B Hu $u^{3,8,9}$
}

For numbered affiliations see end of the article.

Correspondence to: F B Hu, Department of Nutrition, Harvard T.H. Chan School of Public Health, Boston, MA 02115, USA

fhu@hsph.harvard.edu Additional material is published online only. To view please visit the journal online.

Cite this as: $B M J$ 2019;365:L2110 http://dx.doi.org/10.1136/bmi.l2110

Accepted: 25 April 2019

\section{ABSTRACT}

OBJECTIVE

To evaluate the association of changes in red meat consumption with total and cause specific mortality in women and men.

\section{DESIGN}

Two prospective cohort studies with repeated measures of diet and lifestyle factors.

\section{SETTING}

Nurses' Health Study and the Health Professionals Follow-up Study, United States.

\section{PARTICIPANTS}

53553 women and 27916 men without cardiovascular disease or cancer at baseline.

MAIN OUTCOME MEASURE

Death confirmed by state vital statistics records, the national death index, or reported by families and the postal system.

\section{RESULTS}

14019 deaths occurred during 1.2 million person years of follow-up. Increases in red meat consumption over eight years were associated with a higher mortality risk in the subsequent eight years among women and men (both $\mathrm{P}$ for trend 0.05 , $\mathrm{P}$ for heterogeneity $=0.97$ ). An increase in total red meat consumption of at least half a serving per day was associated with a $10 \%$ higher mortality risk (pooled hazard ratio 1.10, 95\% confidence interval 1.04 to 1.17). For processed and unprocessed red meat consumption, an increase of at least half a serving per day was associated with a $13 \%$ higher mortality risk $(1.13,1.04$ to 1.23$)$ and a $9 \%$ higher mortality risk $(1.09,1.02$ to 1.17$)$, respectively. A decrease in consumption of processed or unprocessed red meat of at least half a serving per day was not associated with mortality risk. The association between increased red meat consumption

\section{WHAT IS ALREADY KNOWN ON THIS TOPIC}

Higher consumption of red meat has been associated with an increased risk of chronic diseases and premature death

Evidence is lacking about how changes in red meat consumption over time influence mortality, or what kind of alternative food choices would benefit health

\section{WHAT THIS STUDY ADDS}

Increases in red meat consumption, especially processed meat, were associated with a higher risk of death

Decreases in red meat consumption and simultaneous increases in healthy alternative food choices over time were associated with a lower mortality risk Further evidence supports the health benefits of replacing red and processed meat consumption with healthy protein sources, whole grains, or vegetables and mortality risk was consistent across subgroups defined by age, physical activity, dietary quality, smoking status, or alcohol consumption.

\section{CONCLUSION}

Increases in red meat consumption, especially processed meat, were associated with higher overall mortality rates.

\section{Introduction}

A large body of evidence has shown that higher red meat consumption, especially processed red meat, is associated with an increased risk of type 2 diabetes, ${ }^{1}$ cardiovascular disease, ${ }^{2}$ certain types of cancer, including colorectal cancer, ${ }^{3}$ and mortality. ${ }^{4}{ }^{5}$ Consumption of processed red meat (eg, bacon, hot dogs, and sausages) has been associated with additional health outcomes, including chronic obstructive pulmonary disease, ${ }^{6}$ heart failure, ${ }^{7}$ and hypertension. ${ }^{8}$ Components of red and processed meats such as proatherosclerotic lipids (eg, saturated fat), ${ }^{9}$ potential carcinogens (eg, polycyclic aromatic hydrocarbons), ${ }^{10}$ sodium, and preservatives could contribute to adverse health outcomes.

Red meat is a major component of dietary patterns in Western populations. The average consumption of red meat in the United States has decreased in recent decades, but it remains more than twice the global average. ${ }^{11}$ Several epidemiological studies have analyzed the relation between red meat consumption and mortality risk. In this study, we examined whether changes in red meat intake are associated with subsequent risk of total and cause specific mortality.

We analyzed the association of changes in red meat consumption over eight years with mortality risk during the subsequent eight years. Participants were US women from the Nurses' Health Study and US men from the Health Professionals Follow-up Study. The Dietary Guidelines for Americans 2015-2020 include the recommendation: "Strategies to increase the variety of protein foods include incorporating seafood as the protein foods choice in meals . . . and using legumes or nuts and seeds in mixed dishes instead of some meat or poultry." 12 Therefore, we used statistical models to estimate the effects of replacing red meat with equivalent amounts of other protein sources, such as nuts, poultry, fish, dairy, eggs, and legumes, and whole grains and vegetables.

\section{Methods}

Study population

The Nurses' Health Study is a prospective cohort study of 121700 US registered female nurses aged 
30-55 at enrollment. The study started in 1976 and nurses completed a baseline questionnaire about demographic factors, diet habits, lifestyle, and medical history. The Health Professionals Follow-up Study was established in 1986 when 51529 US male health professionals aged 40-75 returned a baseline questionnaire about detailed medical history, lifestyle, and usual diet. In both cohorts, questionnaires were completed biennially after baseline to collect and update information on lifestyle and occurrence of new onset diseases. The follow-up rates were approximately $90 \%$ for both cohorts. Detailed descriptions of the cohorts have been published elsewhere. ${ }^{13} 14$

The baseline of the current analysis was set as 1994, which is eight years after 1986 when detailed information on diet, physical activity, and other lifestyle factors was collected for both cohorts. The end of follow-up was 2010. We excluded participants who had a history of heart disease, stroke or cancer, missing information on diet and lifestyle covariates, extreme energy intake (men: $<800$ or $>4200 \mathrm{kcal} /$ day; women: $<500$ or $>3500 \mathrm{kcal} /$ day; $1 \mathrm{kcal}=4.18 \mathrm{~kJ}=0.00418 \mathrm{MJ}$ ), or those who died before baseline (that is, 1994). The final analysis included 53553 women and 27916 men.

\section{Dietary assessment}

The two cohorts completed a validated semiquantitative food frequency questionnaire in 1986 and every four years thereafter. Participants were asked how often, on average, they consumed a standard portion of each food in the past year. Frequency response categories ranged from never or less than once a month, to six or more times each day. Questionnaire items on unprocessed red meat (one serving, $85 \mathrm{~g}$ ) included beef, pork, and lamb as a main dish; hamburger; and beef, pork, or lamb as a sandwich or mixed dish. Items on processed red meat included bacon (one serving, two slices, $13 \mathrm{~g}$ ), hot dogs (one serving, one hot dog, $45 \mathrm{~g}$ ), and sausage, salami, bologna, and other processed red meats (one serving, one piece, $28 \mathrm{~g}$ ). Total red meat included unprocessed and processed red meat. The reproducibility and validity of the food frequency questionnaire have been described elsewhere ${ }^{15-17}$ and show good correlations with several weeks of food records. ${ }^{16}$ For the Health Professionals Follow-up Study, the corrected correlation coefficients between the food frequency questionnaire and multiple dietary records were 0.59 for unprocessed red meat and 0.52 for processed red meat ${ }^{18}$; we observed similar correlations for the Nurses' Health Study. ${ }^{16}$ In a subcohort of the Nurses' Health Study ( $n=3690)$, higher red meat consumption was associated with unfavorable plasma concentrations of inflammatory and glucose metabolic biomarkers. ${ }^{19}$ In the current study, we calculated a modified diet score of the alternative healthy eating index to assess overall diet quality after removing the red meat components. ${ }^{17}$

\section{Ascertainment of mortality}

Death from any cause was the primary outcome of this analysis. We identified deaths by using the state vital statistics records, the national death index, reports by families, and the postal system. ${ }^{20}$ Using these methods, we ascertained $98 \%$ of deaths in each cohort. ${ }^{20}$ We sought death certificates for all deaths, and when appropriate, requested permission from the next of kin to review medical records. A physician reviewed death certificates and medical records and determined the underlying cause of death according to the ICD-8 and ICD-9 (international classification of diseases, eighth and ninth revisions). We grouped causes of death into six major categories (supplementary table 1).

\section{Covariates measurement}

Information on potential confounders was assessed and updated biennially. These confounders included age, race, family history of myocardial infarction, diabetes or cancer, weight, smoking status, aspirin use, multivitamin use, menopausal status and postmenopausal hormone therapy use for women, physical activity, and physician diagnosed hypertension, diabetes, or hypercholesterolemia. Alcohol consumption was assessed and updated from the food frequency questionnaire every four years. Height and weight were used to calculate body mass index. Detailed descriptions of the validity and reproducibility of self reported body weight, physical activity, and alcohol consumption have been published elsewhere. ${ }^{21-23}$

\section{Statistical analysis}

We calculated the follow-up person years from the date of returning the 1994 questionnaire to the date of death or the end of follow-up, whichever came first. Updated eight year change in red meat consumption was used as the time varying exposure. We used time dependent Cox proportional hazards regression to estimate the hazard ratios and 95\% confidence intervals of total and cause specific mortality in the subsequent eight years; that is, changes in red meat consumption between 1986 and 1994 predicted mortality in 19942002, and changes in red meat consumption between 1994 and 2002 predicted mortality in 2002-10. We divided participants into five categories based on their changes in red meat consumption: two increase categories (increase of $>0.5$ serving per day or 3.5 servings per week; increase of 0.15-0.5 serving per day or 1-3.5 servings per week); two decrease categories (decrease of $>0.5$ serving per day or 3.5 servings per week; decrease of 0.15-0.5 serving per day or 1-3.5 servings per week), and one reference category (increase or decrease of $<0.15$ serving per day or $<1$ serving per week). We also calculated hazard ratios and the corresponding 95\% confidence intervals for changes in red meat consumption.

We adjusted multivariable models for initial age, calendar year as the underlying time scale, race (white $v$ other), family history of myocardial infarction, diabetes, or cancer (yes $v$ no), initial aspirin use (yes $v$ no), and initial multivitamin use (yes $v$ no). We also adjusted for initial consumption of red meat (in fifths); body mass index categories $(<23,23-24.9,25-29.9,30-34.9$, and $\geq 35$ ); menopausal status and hormone therapy use in 
women (premenopausal, postmenopausal and hormone therapy never user, postmenopausal and hormone therapy current user, postmenopausal and hormone therapy past user, or missing indicator); simultaneous changes in smoking status (never to never, never to current, former to former, former to current, current to former, current to current, or missing indicator); initial and simultaneous changes in physical activity, alcohol consumption, total energy intake, and other main food groups, including vegetables, fruits, whole grains, and sugar-sweetened beverages (all in fifths). In an additional model, we further adjusted for initial history of hypertension, hypercholesterolemia, or diabetes (all yes $v$ no), and simultaneous weight change (in fifths), which were potential mediators of the association between red meat changes and mortality. Unprocessed and processed red meat changes were also estimated separately. Stratified analyses were performed a priori by treating total red meat change as a continuous variable according to initial age, body mass index, smoking status, physical activity, alcohol consumption, and modified alternative healthy eating index. The significance of the interaction terms was tested by including cross product terms for each category and change in red meat consumption in the multivariable models.

We also examined the risk of death associated with a decrease in red meat by one serving per day and a simultaneous increase of one serving per day of poultry (no skin), fish, dairy products, eggs, legumes, nuts, whole grains, or vegetables (no legumes). We included concurrent changes in all these food sources, in addition to red meat, in the same multivariable model. The difference in the $\beta$ coefficients for change in red meat and change in the alternative food was used to estimate the hazard ratio; the corresponding variances and covariance were used to estimate $95 \%$ confidence intervals. ${ }^{24}$

In secondary analyses, we estimated short term (four year) and long term (12 year) changes in red meat consumption for associations with total mortality (four year change in red meat consumption predicted four year follow-up, and 12 year change in red meat consumption predicted 12 year follow-up). We also modeled associations of a decrease of one serving per day of red meat substituted with an alternative food over four years with total mortality in the subsequent four years, and the same substitution over 12 years with total mortality in the subsequent 12 years.

We calculated hazard ratios and 95\% confidence intervals from the different models separately for each cohort, and then we pooled the results by using an inverse variance weighted meta-analysis with the fixed effects model. Analyses were performed with SAS version 9.4 for UNIX (SAS Institute, Cary, NC). Statistical tests were two sided and a $\mathrm{P}$ value less than 0.05 was considered statistically significant.

\section{Patient and public involvement}

No patients were involved in setting the research question or the outcome measures, nor were they involved in the design and implementation of the study. No plans exist to involve patients in dissemination.

\section{Results}

In the Nurses' Health Study, we identified 8426 deaths during the follow-up (804685 person years): 1774 deaths from cardiovascular disease, 3138 from cancer, 939 from neurodegenerative diseases, 751 from respiratory diseases, and 1824 from other causes. In the Health Professionals Follow-up Study, we identified 5593 deaths during follow-up (409073 person years): 1754 deaths from cardiovascular disease, 1754 from cancer, 434 from respiratory diseases, 375 from neurodegenerative diseases, and 1276 from other causes.

Table 1 shows red meat consumption from 1986 to 2006. Total red meat consumption (mean serving per day) decreased from 1.05 to 0.74 in women, and from 1.14 to 1.03 in men. Processed meat consumption decreased from 0.30 to 0.21 (from approximately 9 to $6 \mathrm{~g} /$ day) in women, and remained at about 0.35 (approximately $10 \mathrm{~g} /$ day) in men. Unprocessed meat consumption decreased from 0.76 to 0.53 (from approximately 65 to $45 \mathrm{~g}$ /day) in women, and from 0.78 to 0.69 (from approximately 66 to $59 \mathrm{~g} /$ day) in men.

Table 2 shows distributions of lifestyle characteristics in 1994 based on eight year (1986-1994) changes in total red meat consumption. During this period, more women and men decreased red meat consumption than participants who increased consumption. Compared with the participants with a relatively stable consumption of red meat, those who increased or decreased consumption were more likely to have started with a less healthy diet consisting of a higher intake of energy and alcohol; they were also more likely to be less physically active, have a higher body mass index, and be current smokers. Participants who decreased their consumption of red meat were more likely to have hypercholesterolemia. We found that consumption of red meat changed in the same direction as changes in daily energy intake, and in the opposite direction to changes in dietary quality score.

Table 3 shows associations of changes in red meat consumption with total mortality across categories of total red meat, processed meat, and unprocessed meat. In the age adjusted model of pooled women and men, an increase in red meat consumption was associated with a higher risk of death, while a decrease in red meat consumption was related to a lower risk of death. Further adjustment of initial traditional risk factors, initial and concurrent changes in lifestyle, calorie intake, and other food consumption did not substantially change the results for increased consumption (when consumption was increased by more than half a serving per day, pooled hazard ratio 1.10, 95\% confidence interval 1.04 to 1.17$)$. However, the initially observed association for decreased consumption was no longer evident after multivariable adjustment (when consumption was decreased by more than half a serving per day, pooled hazard ratio 


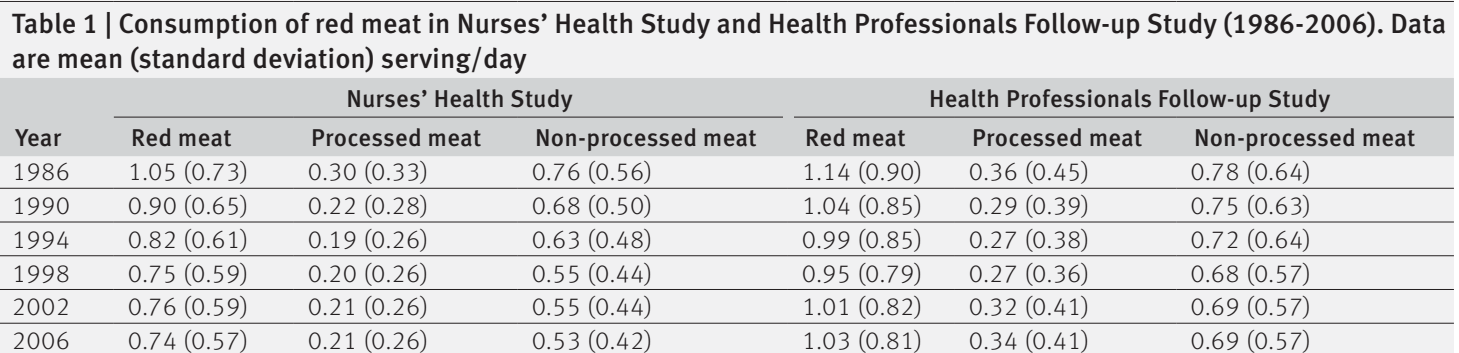

$0.97,95 \%$ confidence interval 0.91 to 1.03 ). The magnitudes of associations were consistent among women and men (P for heterogeneity=0.97).

Changes in processed meat and unprocessed meat were significantly associated with mortality (both pooled $\mathrm{P}$ for trend<0.05), and such associations were mainly driven by the increased consumption (table 3). We found that changes in processed meat consumption had a stronger association with mortality than changes in unprocessed meat consumption (table 3). Further adjustment for hypertension, diabetes, and hypercholesterolemia, and concurrent weight change did not substantially alter the results (supplementary table 2). When we adjusted the model for socioeconomic status represented by the educational attainment of the nurses and their husbands, the results in the Nurses' Health Study did not change (data not shown).

Associations of four year and 12 year changes in consumption of total red meat, processed meat, and unprocessed meat with total mortality (four year and 12 year risk of death, respectively) were in general similar to the results from the eight year analysis (supplementary tables 3 and 4, respectively). In the pooled results for women and men, an increase of more than half a serving per day of red meat over four years was associated with a $20 \%$ higher mortality risk in the subsequent four years (pooled hazard ratio 1.20, 95\% confidence interval 1.13 to 1.27 ); and an increase of more than half a serving per day of red meat over 12 years was associated with a $12 \%$ higher mortality risk in the subsequent 12 years (1.12, 1.03 to 1.22). However, a decrease in red meat consumption was not associated with mortality in any of the analyses.

The association of changes in red meat consumption with mortality was consistent across participants, irrespective of age, physical activity level, dietary quality, smoking status, or alcohol consumption (fig 1). Among normal weight participants, an increase in one serving per day of red meat over eight years was associated with a 13\% higher risk of death (pooled hazard ratio 1.13, 95\% confidence interval 1.06 to 1.20). However, among participants who were overweight or obese, the corresponding increased risk was lower (1.06, 1.01 to 1.13 , pooled $\mathrm{P}$ for interaction=0.02; fig 1). This interaction was significant in women only ( $\mathrm{P}$ for interaction=0.03; fig 1 ).

In multivariable analyses, an eight year change in red meat consumption as a continuous variable showed a trend of direct associations with the subsequent eight year risk of total mortality and most causes of death among women and men (supplementary fig 1). In the pooled meta-analysis of women and men, an increase of one serving per day of total red meat was associated with a $9 \%$ higher risk of all cause mortality (pooled hazard ratio 1.09 , 95\% confidence interval 1.04 to 1.13); an increase of one serving per day of processed meat and unprocessed meat was associated with a $17 \%$ and $5 \%$ higher risk of all cause death, respectively (processed meat: pooled hazard ratio 1.17, 95\% confidence interval 1.08 to 1.26; unprocessed meat: $1.05,1.00$ to 1.11). We observed significant positive associations of changes in red meat with deaths from cardiovascular disease and respiratory disease. In particular, an increase of one serving per day of processed meat over eight years was associated with a $19 \%$ higher risk of death from cardiovascular disease $(1.19,1.03$ to 1.38$)$ and a $57 \%$ higher risk of death from neurodegenerative disease $(1.57,1.21$ to 2.03$)$ in the subsequent eight years. Associations of changes in unprocessed meat consumption with death from specific causes were weaker and non-significant in general (except for death from respiratory disease or other disease) compared with changes in processed meat consumption.

Table 4 shows the eight year all cause mortality associated with a decrease of one serving per day of red meat consumption and a simultaneous increase of one serving per day of another major dietary protein source, whole grains, or vegetables over the previous eight years. Overall, we found a decrease in red meat and an increase in whole grains, vegetables, or other protein sources was associated with a lower risk of death among women and men. The pooled results showed a substantially lower mortality risk with a decrease in red meat consumption and a simultaneous increase in the consumption of nuts (pooled hazard ratio 0.81, 95\% CI 0.79 to 0.84$)$; fish $(0.83,0.76$ to 0.91$)$; whole grains $(0.88,0.83$ to 0.94$)$; poultry without skin $(0.90,0.86$ to $0.95)$; vegetables without legumes $(0.90,0.87$ to 0.93$)$; dairy (0.92, 0.86 to 0.99$)$; eggs (0.92, 0.89 to 0.96$)$; or legumes (0.94, 0.90 to 0.99). A decrease in processed meat and a simultaneous increase in whole grains, vegetables, or other protein sources was even more strongly associated with lower total mortality, with the largest reductions in risk seen with increases in nuts (0.74, 0.70 to 0.79$)$ and fish $(0.75,0.68$ to 0.84$)$. We found that a decrease in unprocessed red meat and a simultaneous increase in other protein sources except for legumes, whole grains, vegetables, or dairy was also associated with a substantially lower risk of death. 


\begin{tabular}{|c|c|c|c|c|c|}
\hline \multirow[b]{2}{*}{ Characteristics } & \multicolumn{2}{|c|}{ Decrease in red meat } & \multirow[b]{2}{*}{$\begin{array}{l}\text { Reference (change of } \\
<0.15 \text { serving/day) } \neq\end{array}$} & \multicolumn{2}{|c|}{ Increase in red meat } \\
\hline & $>0.5$ serving $/$ day $^{*}$ & $\begin{array}{l}0.15-0.5 \\
\text { serving/dayt }\end{array}$ & & $\begin{array}{l}0.15-0.5 \\
\text { serving/dayt }\end{array}$ & $>0.5$ serving $/$ day* $^{*}$ \\
\hline \multicolumn{6}{|l|}{ Nurses' Health Study: } \\
\hline No of participants & 17809 & 13571 & 12270 & 6372 & 3531 \\
\hline Initial red meat intake (serving/day) & $1.6(0.7)$ & $0.9(0.5)$ & $0.6(0.5)$ & $0.7(0.4)$ & $0.8(0.5)$ \\
\hline Age (years) & $59.4(7.1)$ & $60.1(7.1)$ & $60.6(7.0)$ & $60.5(7.0)$ & $60.4(7.2)$ \\
\hline Initial alcohol intake (g/day) & $6.2(10.7)$ & $6.0(10.1)$ & $6.1(10.2)$ & $6.5(11.0)$ & $6.5(11.7)$ \\
\hline Change in alcohol intake (g/day) & $-1.5(7.9)$ & $-1.1(7.4)$ & $-0.9(7.5)$ & $-0.9(8.1)$ & $-0.9(9.0)$ \\
\hline Initial physical activity (MET hours/week) & $13.0(18.8)$ & $14.6(20.4)$ & $15.9(21.8)$ & $14.0(19.0)$ & $13.1(18.5)$ \\
\hline Change in physical activity (MET hours/week) & $0.8(21.1)$ & $0.2(20.5)$ & $-0.6(22.0)$ & $-0.3(20.0)$ & $-0.4(19.2)$ \\
\hline Initial total energy intake (kcal/day) & $1961(512)$ & $1713(488)$ & $1618(483)$ & $1645(498)$ & $1731(509)$ \\
\hline Change in total energy intake (kcal/day) & $-244(464)$ & $-36(429)$ & $65(426)$ & $182(429)$ & $358(473)$ \\
\hline Initial body mass index & $25.4(4.8)$ & $25.0(4.5)$ & $24.9(4.5)$ & $25.3(4.7)$ & $25.9(4.9)$ \\
\hline Weight change (lb) & $5.7(14.1)$ & $6.3(13.4)$ & $7.0(13.6)$ & $8.3(14.8)$ & $9.0(16.1)$ \\
\hline Initial AHEI score & $45.9(9.4)$ & $48.3(9.8)$ & $49.6(10.3)$ & $48.3(10.2)$ & $47.2(9.9)$ \\
\hline Change in AHEI score & $1.2(8.1)$ & $0.3(8.0)$ & $-0.3(8.0)$ & $-0.5(8.1)$ & $-0.7(8.2)$ \\
\hline $\begin{array}{l}\text { Parental history of myocardial } \\
\text { infarction before age } 65(\%)\end{array}$ & 19.1 & 18.7 & 19.0 & 19.1 & 18.4 \\
\hline Hypertension (\%) & 36.5 & 34.7 & 35.1 & 36.7 & 38.5 \\
\hline High cholesterol level (\%) & 51.7 & 48.9 & 48.2 & 46.1 & 45.7 \\
\hline Type 2 diabetes (\%) & 5.7 & 4.8 & 5.0 & 5.5 & 7.4 \\
\hline Current postmenopausal hormone user (\%) & 37.1 & 38.1 & 37.5 & 38.3 & 34.8 \\
\hline Current smoker (\%) & 20.2 & 18.8 & 17.5 & 21.1 & 23.1 \\
\hline \multicolumn{6}{|l|}{ Health Professionals Follow-up Study: } \\
\hline No of participants & 7480 & 5878 & 6633 & 4321 & 3604 \\
\hline Initial red meat intake (serving/day) & $1.8(0.9)$ & $1.1(0.6)$ & $0.7(0.6)$ & $0.8(0.6)$ & $1.0(0.7)$ \\
\hline Age (years) & $59.9(9.0)$ & $60.1(9.0)$ & $61.1(9.3)$ & $60.9(9.2)$ & $61.0(9.3)$ \\
\hline Initial alcohol intake (g/day) & $12.0(15.8)$ & $11.1(14.7)$ & $10.4(14.0)$ & $12.0(15.2)$ & $12.3(16.2)$ \\
\hline Change in alcohol intake (g/day) & $-0.7(12.0)$ & $-0.2(11.1)$ & $0.1(10.5)$ & $-0.1(11.5)$ & $0.2(12.7)$ \\
\hline Initial physical activity (MET hours/week) & $17.3(18.5)$ & $19.2(19.2)$ & $21.2(20.7)$ & $19.7(19.7)$ & $17.7(19.0)$ \\
\hline Change in physical activity (MET hours/week) & $5.2(27.0)$ & $4.5(26.2)$ & $4.0(27.7)$ & $3.5(29.3)$ & $2.9(27.9)$ \\
\hline Initial total energy intake (kcal/day) & $2216(595)$ & $1961(566)$ & $1849(555)$ & $1888(559)$ & $1974(587)$ \\
\hline Change in total energy intake (kcal/day) & $-256(529)$ & $-38(486)$ & $45(477)$ & $199(483)$ & $429(531)$ \\
\hline Initial body mass index & $25.6(3.2)$ & $25.2(3.0)$ & $24.9(2.9)$ & $25.3(3.1)$ & $25.7(3.3)$ \\
\hline Weight change (lb) & $2.5(11.2)$ & $3.3(10.5)$ & $4.1(10.2)$ & $4.8(10.7)$ & $5.7(12.2)$ \\
\hline Initial AHEI score & $46.9(9.6)$ & $49.6(10.0)$ & $52.2(10.5)$ & $50.5(10.5)$ & $48.8(10.3)$ \\
\hline Change in AHEI score & $2.4(9.0)$ & $0.8(8.9)$ & $-0.5(9.0)$ & $-0.6(9.0)$ & $-1.0(9.4)$ \\
\hline $\begin{array}{l}\text { Parental history of myocardial infarction } \\
\text { before age } 65(\%)\end{array}$ & 31.9 & 32.7 & 33.6 & 32.2 & 30.6 \\
\hline Hypertension (\%) & 26.7 & 26.2 & 25.0 & 26.0 & 27.9 \\
\hline High cholesterol level (\%) & 39.3 & 37.1 & 33.9 & 34.1 & 32.8 \\
\hline Type 2 diabetes (\%) & 4.6 & 4.2 & 3.3 & 3.9 & 5.1 \\
\hline Current smoker (\%) & 9.1 & 7.9 & 6.6 & 8.4 & 10.8 \\
\hline \multicolumn{6}{|c|}{$\begin{array}{l}\text { AHEl=alternative healthy eating index; MET=metabolic equivalent of task. } \\
1 \mathrm{kcal}=4.18 \mathrm{~kJ}=0.00418 \mathrm{MJ} \text {. } \\
\text { Values are standardized to the age distribution of the study population except for age. } \\
\text { * }>3.5 \text { servings } / \text { week. } \\
\dagger 1-3.5 \text { servings } / \text { week. } \\
\neq<1 \text { serving/week. }\end{array}$} \\
\hline
\end{tabular}

Supplementary table 5 shows the associations of changes in all the above food groups including red meat with eight year mortality in the replacement modeling analyses. We found similar results with changes over four and 12 years (supplementary tables 6 and 7).

\section{Discussion}

In two large prospective cohorts of US women and men, we found an increase in red meat consumption over eight years was directly associated with risk of death during the subsequent eight years, and was independent of initial red meat intake and concurrent changes in lifestyle factors. This association with mortality was observed with increased consumption of processed and unprocessed meat, but was stronger for processed meat. A decrease in total red meat consumption and a simultaneous increase in the consumption of nuts, fish, poultry without skin, dairy, eggs, whole grains, or vegetables over eight years was associated with a lower risk of death in the subsequent eight years. These findings suggest that a change in protein source or eating healthy plant based foods such as vegetables or whole grains can improve longevity. We also observed the same associations with mortality and replacement foods in shorter term (four year) and longer term (12 year) studies.

\section{Strengths and weaknesses in relation to other studies}

Systematic reviews and meta-analyses of prospective cohort studies have indicated an adverse association of consumption of red meat, in particular processed 


\begin{tabular}{|c|c|c|c|c|c|c|}
\hline \multirow[b]{2}{*}{ Mortality } & \multicolumn{2}{|c|}{ Decrease in red meat } & \multirow{2}{*}{$\begin{array}{l}\text { Reference (change of } \\
<0.15 \text { serving/day) } \neq\end{array}$} & \multicolumn{2}{|c|}{ Increase in red meat } & \multirow[b]{2}{*}{$\mathrm{P}$ for trend } \\
\hline & $>0.5$ serving $/$ day* & $0.15-0.5$ serving/dayt & & $0.15-0.5$ serving/day* & $>0.5$ serving $/$ day $\dagger$ & \\
\hline \multicolumn{7}{|c|}{ Nurses' Health Study ( $n=53553)$ : } \\
\hline \multicolumn{7}{|c|}{ Red meat: } \\
\hline Deaths/person years & $1903 / 201574$ & $2062 / 195475$ & $2447 / 218138$ & $1239 / 118300$ & 775/71198 & \\
\hline Model 1 & 0.91 (0.85 to 0.98$)$ & 0.92 (0.87 to 0.98$)$ & 1 & 1.03 (0.96 to 1.10 ) & $1.12(1.03$ to 1.21$)$ & $<0.001$ \\
\hline Model 2 & 0.97 (0.90 to 1.04$)$ & $0.98(0.92$ to 1.04$)$ & 1 & 1.06 (0.99 to 1.14$)$ & 1.11 (1.02 to 1.21$)$ & 0.002 \\
\hline \multicolumn{7}{|l|}{ Processed meat: } \\
\hline Deaths/person years & $349 / 35801$ & $1194 / 130565$ & $5670 / 539651$ & $946 / 78793$ & $267 / 19875$ & \\
\hline Model 1 & $0.98(0.86$ to 1.11$)$ & 0.91 (0.84 to 0.98$)$ & 1 & $1.14(1.06$ to 1.22$)$ & $1.37(1.21$ to 1.55$)$ & $<0.001$ \\
\hline Model 2 & 1.01 (0.89 to 1.14$)$ & $0.97(0.90$ to 1.05$)$ & 1 & $1.10(1.03$ to 1.18$)$ & $1.22(1.08$ to 1.39$)$ & 0.001 \\
\hline \multicolumn{7}{|l|}{ Unprocessed meat: } \\
\hline Deaths/person years & $1433 / 150705$ & $2216 / 202641$ & $3101 / 282839$ & $1187 / 119073$ & $489 / 49427$ & \\
\hline Model 1 & 0.97 (0.89 to 1.05$)$ & $0.95(0.90$ to 1.01$)$ & 1 & $1.03(0.97$ to 1.10$)$ & $1.07(0.97$ to 1.17$)$ & 0.02 \\
\hline Model 2 & $1.00(0.92$ to 1.08$)$ & $1.01(0.95$ to 1.07$)$ & 1 & $1.06(0.99$ to 1.13$)$ & $1.06(0.96$ to 1.17$)$ & 0.21 \\
\hline \multicolumn{7}{|c|}{ Health Professionals Follow-up Study ( $n=27916)$ : } \\
\hline \multicolumn{7}{|c|}{ Red meat: } \\
\hline Deaths/person years & $1124 / 89081$ & $1008 / 79123$ & $1569 / 110243$ & $946 / 70096$ & $946 / 60530$ & \\
\hline Model 1 & $0.87(0.80$ to 0.96$)$ & $0.92(0.85$ to 1.00$)$ & 1 & 0.96 (0.88 to 1.04$)$ & 1.03 (0.95 to 1.13$)$ & 0.001 \\
\hline Model 2 & 0.97 (0.88 to 1.07) & 1.01 (0.93 to 1.10$)$ & 1 & 1.04 (0.96 to 1.14) & 1.10 (1.01 to 1.20$)$ & 0.01 \\
\hline \multicolumn{7}{|l|}{ Processed meat } \\
\hline Deaths/person years & $331 / 26326$ & $796 / 64705$ & $3225 / 248483$ & $883 / 50451$ & $358 / 19107$ & \\
\hline Model 1 & 0.91 (0.79 to 1.05$)$ & 0.94 (0.86 to 1.03) & 1 & 1.11 (1.03 to 1.20$)$ & 1.07 (0.95 to 1.19) & 0.002 \\
\hline Model 2 & $0.95(0.83$ to 1.10$)$ & $1.00(0.91$ to 1.10$)$ & 1 & $1.15(1.06$ to 1.24$)$ & 1.06 (0.94 to 1.19$)$ & 0.01 \\
\hline \multicolumn{7}{|l|}{ Unprocessed meat: } \\
\hline Deaths/person years & $856 / 64559$ & $1150 / 84015$ & $2008 / 140679$ & $910 / 75291$ & $669 / 44528$ & \\
\hline Model 1 & 0.91 (0.82 to 1.00$)$ & $0.96(0.89$ to 1.04$)$ & 1 & $0.96(0.88$ to 1.03$)$ & 1.09 (0.99 to 1.19$)$ & 0.006 \\
\hline Model 2 & $1.00(0.90$ to 1.11$)$ & $1.05(0.97$ to 1.14$)$ & 1 & 1.01 (0.93 to 1.10$)$ & $1.13(1.02$ to 1.24$)$ & 0.12 \\
\hline \multicolumn{7}{|l|}{ Pooled results: } \\
\hline \multicolumn{7}{|l|}{ Red meat: } \\
\hline Model 1 & $0.90(0.85$ to 0.95$)$ & $0.92(0.88$ to 0.97$)$ & 1 & $1.00(0.95$ to 1.06$)$ & 1.08 (1.02 to 1.14) & $<0.001$ \\
\hline Model 2 & 0.97 (0.91 to 1.03$)$ & 0.99 (0.94 to 1.04$)$ & 1 & 1.05 (1.00 to 1.11$)$ & 1.10 (1.04 to 1.17$)$ & $<0.001$ \\
\hline \multicolumn{7}{|l|}{ Processed meat: } \\
\hline Model 1 & 0.95 (0.86 to 1.04) & 0.92 (0.87 to 0.98$)$ & 1 & 1.13 (1.07 to 1.19$)$ & 1.19 (1.10 to 1.30$)$ & $<0.001$ \\
\hline Model 2 & 0.98 (0.90 to 1.08$)$ & 0.99 (0.93 to 1.05$)$ & 1 & 1.12 (1.06 to 1.18$)$ & $1.13(1.04$ to 1.23$)$ & $<0.001$ \\
\hline \multicolumn{7}{|l|}{ Unprocessed meat: } \\
\hline Model 1 & 0.94 (0.89 to 1.00$)$ & $0.96(0.91$ to 1.00$)$ & 1 & $1.00(0.95$ to 1.05$)$ & 1.08 (1.01 to 1.15$)$ & $<0.001$ \\
\hline Model 2 & $1.00(0.94$ to 1.07$)$ & 1.02 (0.98 to 1.08$)$ & 1 & $1.04(0.99$ to 1.10$)$ & 1.09 (1.02 to 1.17$)$ & 0.04 \\
\hline \multicolumn{7}{|c|}{$\begin{array}{l}\text { The exposure was change in red meat consumption over an eight year period, and the outcome was mortality in the subsequent eight years; that is, changes in red meat consumption in } 1986- \\
1994 \text { predicted mortality in 1994-2002, and changes in red meat consumption in 1994-2002 predicted mortality in 2002-10. Model 1: adjusted for age and calendar year. Model 2: model } \\
1 \text { and race (white } v \text { other); initial consumption of red meat (in fifths); initial body mass index ( }<23,23-24.9,25-29.9,30-34.9 \text {, and } \geq 35 \text { ); family history of myocardial infarction, diabetes, and } \\
\text { cancer; updated aspirin use and multivitamin use; menopause and hormone therapy status in women (premenopausal, postmenopausal and hormone therapy never user, postmenopausal and } \\
\text { hormone therapy current user, postmenopausal and hormone therapy past user, or missing indicator); and simultaneous changes in other lifestyle factors: smoking status (never to never, never } \\
\text { to current, former to former, former to current, current to former, current to current, or missing indicator); initial and changes in physical activity, alcohol consumption, total energy intake, and } \\
\text { other food groups, that is, vegetables, fruits, whole grains, and sugar-sweetened beverages (all in fifths). } \\
\text { * }>3.5 \text { servings/week. } \\
+1-3.5 \text { servings/week. } \\
\neq<1 \text { serving/week. }\end{array}$} \\
\hline
\end{tabular}

meat, with mortality. ${ }^{2627}$ For example, a recent metaanalysis that summarized 17 prospective cohorts suggested that total red meat consumption was statistically significantly associated with increased risk of death, and this risk was mostly because of processed meat. ${ }^{27}$ One serving of processed meat per day was associated with a $15 \%$ higher risk of all cause mortality (hazard ratio 1.15, 95\% confidence interval 1.11 to 1.19$)$, a $15 \%$ higher risk of cardiovascular death $(1.15,1.07$ to 1.24$)$, and an $8 \%$ higher risk of cancer death (1.08, 1.06 to 1.11); similar results were shown for total red meat consumption. Unprocessed meat consumption was only associated with mortality in the US populations, but not in European or Asian populations. ${ }^{27}$ A recent Japanese study did not find any strong association between red meat consumption and cardiovascular disease death. ${ }^{28}$ However, the consumption level was much lower in the Japanese population than in our cohorts. Also, the Japanese study did not examine changes in red meat intake and subsequent mortality risk. Our previous analysis in the same cohorts indicated that a higher consumption of red meat was associated with an increased risk of all cause, cardiovascular, and cancer mortality. ${ }^{29}$ However, none of these studies considered changes in consumption of red meat. Because people's eating behaviors change over time, it is important to examine whether changes in red meat intake influence subsequent health outcomes. Our current findings are consistent with previous evidence and extend the results. We have shown that short, medium, and long term changes in consumption of red meat, processed meat, and unprocessed meat were all directly associated with mortality, irrespective of the initial 


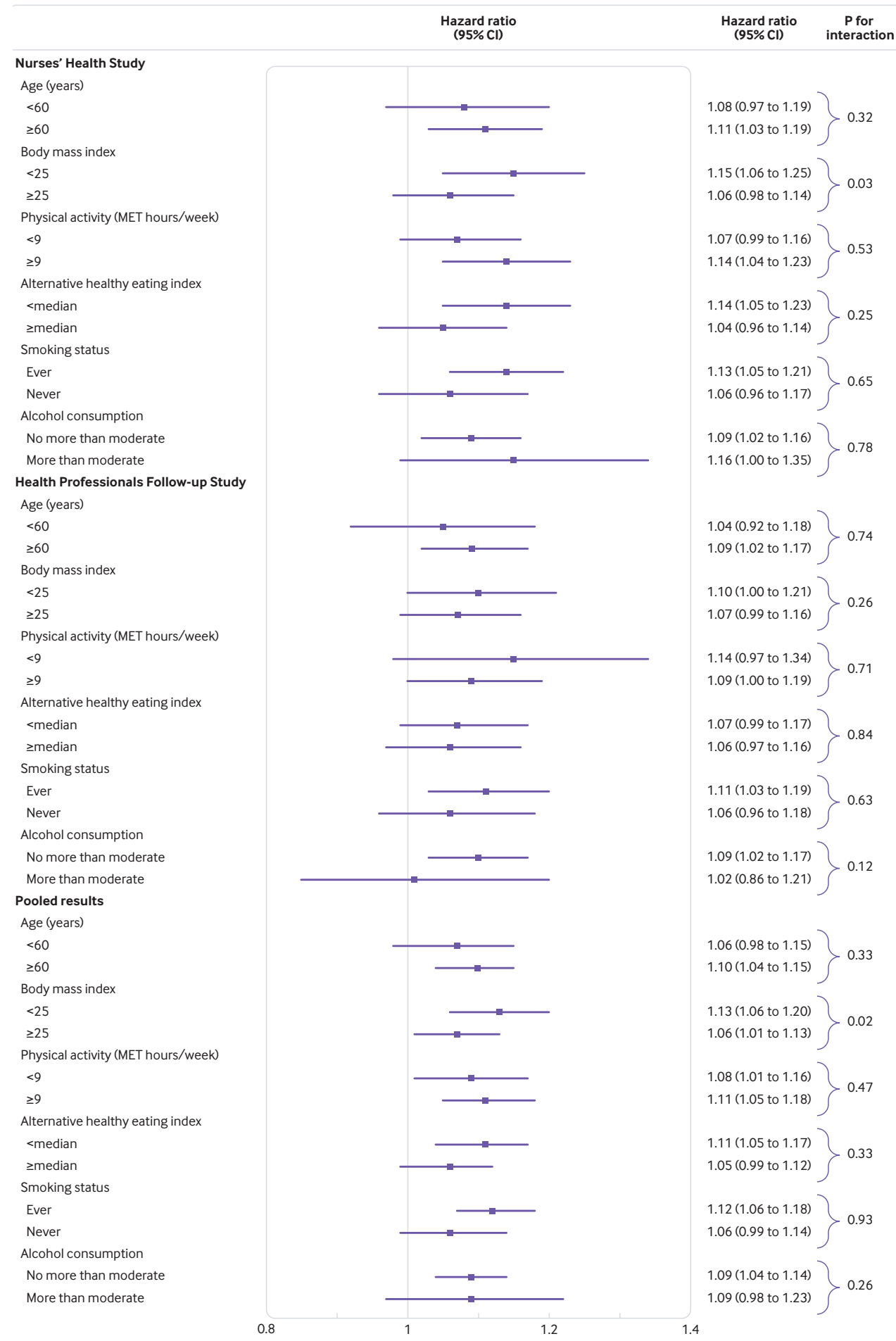

Fig 1 | Hazard ratios (95\% confidence intervals) for all cause mortality associated with an increase in red meat consumption of one serving per day over eight years according to characteristics of participants. Cox proportional hazards models were adjusted for initial age (years); race (white $v$ other); family history of myocardial infarction, diabetes, or cancer (yes $v$ no); initial aspirin use (yes $v$ no) and multivitamin use (yes $v$ no); initial consumption of red meat (in fifths); body mass index categories ( $(23,23-24.9,25-29.9,30-34.9$, and $\geq 35)$; menopausal status and hormone therapy use in women (premenopausal, postmenopausal and hormone therapy never user, postmenopausal and hormone therapy current user, postmenopausal and hormone therapy past user, or missing indicator); simultaneous changes in smoking status (never to never, never to current, former to former, former to current, current to former, current to current, or missing indicator); initial and simultaneous changes in physical activity, alcohol intake, total energy intake, and other main food groups, including vegetables, fruits, whole grains, and sugar-sweetened beverages (all in fifths). P for interaction was calculated using the likelihood ratio test. The cut-off point of physical activity was defined as $150 \mathrm{~min} /$ week at a moderate level or at least $75 \mathrm{~min} /$ week at a vigorous level (equivalent to at least nine MET hours/week) as recommended. ${ }^{25}$ Moderate alcohol consumption was defined as equivalent to $14 \mathrm{~g} /$ day in women and $28 \mathrm{~g} /$ day in men; alternative healthy eating index higher or equal to versus lower than median in each cohort. MET=metabolic equivalent of task 


\begin{tabular}{|c|c|c|c|c|c|c|c|c|}
\hline Mortality & Nuts & $\begin{array}{l}\text { Poultry } \\
\text { without skin }\end{array}$ & Fish & Dairy & Eggs & Legumes & Whole grains* & $\begin{array}{l}\text { Vegetables } \\
\text { without legumest }\end{array}$ \\
\hline \multicolumn{9}{|l|}{ Nurses' Health Study: } \\
\hline Red meat & $\begin{array}{l}0.79 \\
(0.75 \text { to } 0.83)\end{array}$ & $\begin{array}{l}0.83 \\
(0.77 \text { to } 0.89)\end{array}$ & $\begin{array}{l}0.84 \\
(0.74 \text { to } 0.95)\end{array}$ & $\begin{array}{l}0.91 \\
(0.83 \text { to } 1.01)\end{array}$ & $\begin{array}{l}0.94 \\
(0.89 \text { to } 0.99)\end{array}$ & $\begin{array}{l}0.95 \\
(0.85 \text { to } 1.05)\end{array}$ & $\begin{array}{l}0.86 \\
(0.79 \text { to } 0.94)\end{array}$ & $\begin{array}{l}0.88 \\
(0.83 \text { to } 0.93)\end{array}$ \\
\hline Processed meat & $\begin{array}{l}0.68 \\
(0.62 \text { to } 0.74)\end{array}$ & $\begin{array}{l}0.72 \\
(0.65 \text { to } 0.81)\end{array}$ & $\begin{array}{l}0.72 \\
(0.62 \text { to } 0.84)\end{array}$ & $\begin{array}{l}0.79 \\
(0.69 \text { to } 0.90)\end{array}$ & $\begin{array}{l}0.80 \\
(0.72 \text { to } 0.89)\end{array}$ & $\begin{array}{l}0.82 \\
(0.71 \text { to } 0.94)\end{array}$ & $\begin{array}{l}0.74 \\
(0.66 \text { to } 0.84)\end{array}$ & $\begin{array}{l}0.76 \\
(0.69 \text { to } 0.84)\end{array}$ \\
\hline Unprocessed meat & $\begin{array}{l}0.81 \\
(0.77 \text { to } 0.86)\end{array}$ & $\begin{array}{l}0.84 \\
(0.78 \text { to } 0.92)\end{array}$ & $\begin{array}{l}0.86 \\
(0.76 \text { to } 0.99)\end{array}$ & $\begin{array}{l}0.95 \\
(0.85 \text { to } 1.05)\end{array}$ & $\begin{array}{l}0.99 \\
(0.92 \text { to } 1.06)\end{array}$ & $\begin{array}{l}0.98 \\
(0.88 \text { to } 1.10)\end{array}$ & $\begin{array}{l}0.89 \\
(0.81 \text { to } 0.98)\end{array}$ & $\begin{array}{l}0.91 \\
(0.85 \text { to } 0.98)\end{array}$ \\
\hline \multicolumn{9}{|c|}{ Health Professionals Follow-up Study: } \\
\hline Red meat & $\begin{array}{l}0.84 \\
(0.8 \text { to } 0.88)\end{array}$ & $\begin{array}{l}0.98 \\
(0.91 \text { to } 1.04)\end{array}$ & $\begin{array}{l}0.83 \\
(0.72 \text { to } 0.94)\end{array}$ & $\begin{array}{l}0.93 \\
(0.84 \text { to } 1.04)\end{array}$ & $\begin{array}{l}0.90 \\
(0.86 \text { to } 0.95)\end{array}$ & $\begin{array}{l}0.94 \\
(0.89 \text { to } 1.00)\end{array}$ & $\begin{array}{l}0.90 \\
(0.82 \text { to } 0.99)\end{array}$ & $\begin{array}{l}0.92 \\
(0.87 \text { to } 0.97)\end{array}$ \\
\hline Processed meat & $\begin{array}{l}0.80 \\
(0.74 \text { to } 0.86)\end{array}$ & $\begin{array}{l}0.93 \\
(0.84 \text { to } 1.02)\end{array}$ & $\begin{array}{l}0.78 \\
(0.68 \text { to } 0.91)\end{array}$ & $\begin{array}{l}0.89 \\
(0.78 \text { to } 1.01)\end{array}$ & $\begin{array}{l}0.86 \\
(0.79 \text { to } 0.94)\end{array}$ & $\begin{array}{l}0.90 \\
(0.82 \text { to } 0.98)\end{array}$ & $\begin{array}{l}0.86 \\
(0.76 \text { to } 0.96)\end{array}$ & $\begin{array}{l}0.87 \\
(0.80 \text { to } 0.95)\end{array}$ \\
\hline Unprocessed meat & $\begin{array}{l}0.84 \\
(0.79 \text { to } 0.89)\end{array}$ & $\begin{array}{l}0.96 \\
(0.89 \text { to } 1.04)\end{array}$ & $\begin{array}{l}0.82 \\
(0.71 \text { to } 0.94)\end{array}$ & $\begin{array}{l}0.93 \\
(0.83 \text { to } 1.05)\end{array}$ & $\begin{array}{l}0.91 \\
(0.85 \text { to } 0.97)\end{array}$ & $\begin{array}{l}0.94 \\
(0.88 \text { to } 1.01)\end{array}$ & $\begin{array}{l}0.90 \\
(0.81 \text { to } 1.00)\end{array}$ & $\begin{array}{l}0.92 \\
(0.86 \text { to } 0.98)\end{array}$ \\
\hline \multicolumn{9}{|l|}{ Pooled analysis: } \\
\hline Red meat & $\begin{array}{l}0.81 \\
(0.79 \text { to } 0.84)\end{array}$ & $\begin{array}{l}0.90 \\
(0.86 \text { to } 0.95)\end{array}$ & $\begin{array}{l}0.83 \\
(0.76 \text { to } 0.91)\end{array}$ & $\begin{array}{l}0.92 \\
(0.86 \text { to } 0.99)\end{array}$ & $\begin{array}{l}0.92 \\
(0.89 \text { to } 0.96)\end{array}$ & $\begin{array}{l}0.94 \\
(0.90 \text { to } 0.99)\end{array}$ & $\begin{array}{l}0.88 \\
(0.83 \text { to } 0.94)\end{array}$ & $\begin{array}{l}0.90 \\
(0.87 \text { to } 0.93)\end{array}$ \\
\hline Processed meat & $\begin{array}{l}0.74 \\
(0.70 \text { to } 0.79)\end{array}$ & $\begin{array}{l}0.83 \\
(0.78 \text { to } 0.90)\end{array}$ & $\begin{array}{l}0.75 \\
(0.68 \text { to } 0.84)\end{array}$ & $\begin{array}{l}0.84 \\
(0.76 \text { to } 0.92)\end{array}$ & $\begin{array}{l}0.83 \\
(0.78 \text { to } 0.89)\end{array}$ & $\begin{array}{l}0.87 \\
(0.81 \text { to } 0.94)\end{array}$ & $\begin{array}{l}0.80 \\
(0.74 \text { to } 0.87)\end{array}$ & $\begin{array}{l}0.82 \\
(0.77 \text { to } 0.88)\end{array}$ \\
\hline Unprocessed meat & $\begin{array}{l}0.82 \\
(0.79 \text { to } 0.86)\end{array}$ & $\begin{array}{l}0.90 \\
(0.85 \text { to } 0.96)\end{array}$ & $\begin{array}{l}0.84 \\
(0.77 \text { to } 0.93)\end{array}$ & $\begin{array}{l}0.94 \\
(0.87 \text { to } 1.02)\end{array}$ & $\begin{array}{l}0.95 \\
(0.90 \text { to } 0.99)\end{array}$ & $\begin{array}{l}0.95 \\
(0.90 \text { to } 1.01)\end{array}$ & $\begin{array}{l}0.89 \\
(0.83 \text { to } 0.96)\end{array}$ & $\begin{array}{l}0.92 \\
(0.87 \text { to } 0.96)\end{array}$ \\
\hline \multicolumn{9}{|c|}{$\begin{array}{l}\text { Cox proportional hazards models included all protein foods, vegetables and whole grains simultaneously (initial and change, both continuous, per serving), adjusted for age, race (white } v \text { other), } \\
\text { and body mass index in } 1986(<21,21-22,23-24,25-29 \text {, and } \geq 30 \text { ); family history of myocardial infarction, diabetes, and cancer; updated aspirin use; multivitamin use; menopausal status } \\
\text { and use of postmenopausal hormones (premenopausal, postmenopausal and hormone therapy never user, postmenopausal and hormone therapy current user, postmenopausal and hormone } \\
\text { therapy past user, or missing indicator) (only for women); and simultaneous changes in other lifestyle factors: smoking status (never to never, never to current, former, to former, former to current, } \\
\text { current to former, current to current, or missing indicator); and initial and changes (all in fifths) in physical activity, alcohol consumption, total energy intake, and other food groups, that is, fruits } \\
\text { and sugar-sweetened beverages. The results across the two cohorts were pooled using an inverse variance weighted, fixed effect meta-analysis. } \\
\text { *Whole grains included whole grain cold breakfast cereal, dark bread, oatmeal, brown rice, popcorn, bran, and germ. } \\
\text { tVegetables included green leafy vegetables (such as spinach, kale, and lettuce) and cruciferous vegetables (such as cabbage, cauliflower, Brussel sprouts, and broccoli), but no legumes in the } \\
\text { current substitution analysis. }\end{array}$} \\
\hline
\end{tabular}

consumption level. Our observation of an interaction between initial body mass index and mortality is consistent with a previous report of an interaction between initial body mass index and risk of type 2 diabetes. ${ }^{30}$ The pre-existing higher risk of death among people who are overweight or obese could partially account for the relatively modest increased risk after higher red meat consumption compared with that for people of normal weight. However, the subgroup analysis results need to be interpreted with caution because these findings might be due to chance.

Within a relatively fixed daily calorie intake, changes of red meat consumption will be accompanied by changes in other foods, typically protein sources. Previous modeling analyses in our cohorts found that intake of fish, poultry, nuts, legumes, or low fat dairy was associated with a lower risk of total mortality compared with consumption of red meat. ${ }^{29}$ In the current data based modeling investigation, we found that a decrease in red meat consumption at the population level and a simultaneous increase in other protein sources, whole grains, or vegetables was statistically significantly associated with a lower mortality risk. For example, we observed that a decrease of one serving per day of red meat and an increase of one serving per day of fish over eight years was related to a $17 \%$ lower risk of death in the subsequent eight years. In practice, red meat can be replaced by a mixture of healthier protein sources and plant foods with less protein, such as vegetables and whole grains.

\section{Possible explanations and implications}

An adverse effect of red meat consumption on risk of death could be attributable to a combination of factors that promote cardiometabolic disturbances. Saturated fat, cholesterol, and heme iron in red meat could accelerate atherosclerotic processes and affect the incidence and prognosis of hypertension, hypercholesterolemia, endothelial dysfunction, insulin resistance, and type 2 diabetes. ${ }^{3132}$ Because of its high content of saturated fat and cholesterol, randomized controlled trials have shown that consumption of red meat increases low density lipoprotein cholesterol compared with plant sources of protein, such as nuts, soy foods, and other legumes. ${ }^{33}$ Also, the high content of sodium in processed meat is a strong risk factor for hypertension and vascular stiffness, which might increase mortality caused by stroke, myocardial infarction, arterial stiffening, heart failure, and renal insufficiency. ${ }^{34}$ Recent studies have suggested that L carnitine and phosphatidylcholine in red meat and gut microbiota derived metabolite trimethylamine $\mathrm{N}$ oxide might promote atherosclerosis. ${ }^{35} 36$ Additionally, cooked red meat is a source of carcinogens, such as polycyclic aromatic hydrocarbons and heterocyclic amines, which may contribute to cancer risk. ${ }^{10}$ Processed meat appears to be more carcinogenic than unprocessed meat, possibly owing to the abundance of potent nitrosyl heme molecules that form $\mathrm{N}$ nitroso compounds. ${ }^{10}$ In our study, the lack of a strong association between the changes in red meat consumption and cancer death could partially be 
explained by the long latency of tumorigenesis and the heterogeneity of different types of cancer.

The observed association of increased red meat consumption with higher mortality from respiratory disease is consistent with previous reports, ${ }^{37}$ and the formation of reactive nitrogen species could be one major contributor. ${ }^{38}$ In our cohorts, the leading causes of neurodegenerative deaths were dementia (more common in women) and Parkinson's disease (more common in men because female hormones might be neuroprotective against dopamine loss while male hormones are not ${ }^{39}$ ). Processed red meat might be associated with a higher risk of dementia because of the high content of saturated and trans fatty acids and the low content of unsaturated fatty acids, which could lead to blood brain barrier dysfunction and an increase in amyloid $\beta$ aggregation. ${ }^{40} 41$ Processed red meat is also reported to be inversely associated with Parkinson's disease risk through niacin, a vitamin related to nicotinamide metabolism. ${ }^{42} 43$ These mechanisms could partially explain the association between increased processed meat consumption and higher mortality from neurodegenerative disease in women (722 deaths from dementia and 122 from Parkinson's disease), but not in men (153 deaths from dementia and 172 from Parkinson's disease). Our results on neurodegenerative mortality warrant further investigations because of the limited statistical power.

\section{Strengths and weaknesses of this study}

In the current study, we used observational data to investigate associations with mortality, and thus causality cannot be necessarily assumed. Nevertheless, the advantage of long term follow-up periods and individual food changes over several years owing to repeated dietary measures means that our "change to risk" analytical approach partly mimics an interventional trial; in an interventional trial, investigators allocate groups to increase, decrease, or keep stable red meat consumption. Moreover, our "change replace change" substitution analysis imitates flexible intervention arms, and therefore we are able to provide practical recommendations on optimizing food sources to the general public. The results of this change analysis can help to strengthen the causal inference compared with the traditional "baseline to risk" analysis because this type of analysis at least partially accounts for the innate characteristics of participants. The results of our short term (four years), medium term (eight years), and long term (12 years) analyses provide a practical message to the general public of how dynamic changes in red meat consumption are associated with health. Other strengths include large study populations, high rates of long term follow-up, repeated assessment of diet and lifestyle factors, and consistency of the results between the two cohorts.

Our analysis has several limitations. Because of the observational nature of the study, we cannot automatically assume the causality of the observed relations. In particular, residual confounding cannot be completely excluded, although we controlled detailed assessments of demographic and lifestyle factors in the current analyses. We did not assess the reasons for changes in red meat consumption and this could confound the observed associations. For example, the development of latent or active diseases during the corresponding years when the change of red meat occurred would bias the favorable association of a decrease in consumption of red meat with mortality towards the null or even an adverse association. Nevertheless, our results showed a consistent trend of favorable associations of a decrease in consumption of red meat in women and men.

Our study participants mainly consisted of white registered nurses and health professionals. The relative homogeneity of socioeconomic status can help to reduce confounding by socioeconomic status, but it might limit the generalizability of the results to other populations. Nonetheless, previous studies have shown a direct association of red meat and processed meat intake with mortality risk in other populations. ${ }^{44} 45$ The replacement analysis is a statistical modeling strategy that used data across the whole population, without identifying people in the cohort population who actually replaced red meat with the other food groups. Therefore, our results from replacement analysis should be interpreted with caution in the context of statistical modeling, especially when making individualized recommendations.

\section{Conclusion}

Increases in red meat consumption, especially processed meat, over eight years were associated with a higher risk of death in the subsequent eight years in US women and men. Increased consumption of healthier animal or plant foods was associated with a lower risk of death compared with red meat consumption. Our analysis provides further evidence to support the replacement of red and processed meat consumption with healthy alternative food choices.

\section{AUTHOR AFFILIATIONS}

${ }^{1}$ Department of Cardiology, State Key Laboratory of Genetic Engineering, School of Life Sciences and Zhongshan Hospital, Fudan University, Shanghai, China

${ }^{2}$ Ministry of Education Key Laboratory of Public Health Safety, School of Public Health, Fudan University, Shanghai, China

${ }^{3}$ Department of Nutrition, Harvard T.H. Chan School of Public Health, Boston, MA, USA

${ }^{4}$ Department of Epidemiology and Biostatistics, and Ministry of Education Key Laboratory of Environment and Health, and State Key Laboratory of Environmental Health (Incubating), School of Public

Health, Tongji Medical College, Huazhong University of Science and Technology, Wuhan, China

${ }^{5}$ Department of Environmental Health, Harvard T.H. Chan School of Public Health, Boston, MA, USA

${ }^{6}$ Division of Food Sciences and Nutrition, School of Applied Health Sciences and Wellness, and Diabetes Institute, Ohio University, Athens, OH, USA

${ }^{7}$ Department of Preventive Medicine and Public Health, School of Medicine, Universidad Autonoma de Madrid, Madrid, Spain

${ }^{8}$ Department of Epidemiology, Harvard T.H. Chan School of Public Health, Boston, MA, USA

${ }^{9}$ Channing Division of Network Medicine, Department of Medicine, Brigham and Women's Hospital, Harvard Medical School, Boston, MA, USA 
We thank the participants and staff of the Nurses' Health Study and the Health Professionals Follow-up Study for their valuable contributions, and several state cancer registries for their help: $A L$, AZ, AR, CA, CO, CT, DE, FL, GA, ID, IL, IN, IA, KY, LA, ME, MD, MA, MI, NE, NH, NJ, NY, NC, ND, OH, OK, OR, PA, RI, SC, TN, TX, VA, WA, WY. The authors assume full responsibility for analyses and interpretation of these data.

Contributors: $Y Z$ and FBH had the idea for the study. YZ did the data analysis. YL, AP, MSP, and FBH provided statistical expertise. YZ wrote the first draft of the paper. WCW, ER, and FBH obtained funding. All authors contributed to the interpretation of the results and critical revision of the manuscript for important intellectual content, and approved the final version of the manuscript. $\mathrm{YZ}$ and $\mathrm{FBH}$ are the guarantors. The corresponding author attests that all listed authors meet authorship criteria and that no others meeting the criteria have been omitted.

Funding: The cohorts were supported by grants UM1 CA186107 and UM1 CA167552 from the National Institutes of Health. The current study was supported by grants from the National Heart, Lung, and Blood Institute (HL071981, HL034594, HL60712, HL126024), the National Institute of Diabetes and Digestive and Kidney Diseases (DK091718, DK100383, DK112940, DK078616), the Boston Obesity Nutrition Research Center (DK46200). The sources of funding had no role in the design, conduct, analysis, or reporting of this study. YZ was supported by a fellowship from the American Diabetes Association (7-12-MN-34) and the Program for Professor of Special Appointment (Eastern Scholar) at Shanghai Institutions of Higher Learning. The funding sources did not participate in the design or conduct of the study; collection, management, analysis or interpretation of the data; or preparation, review, or approval of the manuscript.

Competing interests: All authors have completed the ICMJE uniform disclosure form at www.icmje.org/coi_disclosure.pdf and declare: support from the National Institutes of Health; National Heart, Lung, and Blood Institute; National Institute of Diabetes and Digestive and Kidney Diseases; and the Boston Obesity Nutrition Research Center for the submitted work; support from the FBH reported being supported by grants HL60712, HL118264, and DK112940 from the National Institutes of Health, and reported receiving research support from the California Walnut Commission and honorariums for lectures from Metagenics and Standard Process and honorariums from Diet Quality Photo Navigation, outside the submitted work.

Ethical approval: The Nurses' Health Study and the Health Professionals Follow-up Study were approved by the institutional review boards at Brigham and Women's Hospital and Harvard T $H$ Chan School of Public Health. The return of the completed self administered questionnaire was considered to imply informed consent.

Data sharing: No additional data available.

Transparency: The lead author (YZ) affirms that the manuscript is an honest, accurate, and transparent account of the study being reported; that no important aspects of the study have been omitted; and that any discrepancies from the study as planned have been explained.

This is an Open Access article distributed in accordance with the Creative Commons Attribution Non Commercial (CC BY-NC 4.0) license, which permits others to distribute, remix, adapt, build upon this work non-commercially, and license their derivative works on different terms, provided the original work is properly cited and the use is noncommercial. See: http://creativecommons.org/licenses/by-nc/4.0/.

1 Pan A, Sun Q, Bernstein AM, et al. Red meat consumption and risk of type 2 diabetes: 3 cohorts of US adults and an updated meta-analysis. Am J Clin Nutr 2011:94:1088-96. doi:10.3945 ajcn.111.018978

2 Micha R, Wallace SK, Mozaffarian D. Red and processed meat consumption and risk of incident coronary heart disease, stroke, and diabetes mellitus: a systematic review and metaanalysis. Circulation 2010;121:2271-83. doi:10.1161/ CIRCULATIONAHA.109.924977

3 Demeyer D, Mertens B, De Smet S, Ulens M. Mechanisms linking colorectal cancer to the consumption of (processed) red meat: review. Crit Rev Food Sci Nutr 2016;56:2747-66. doi:10.1080/1040 8398.2013.873886

4 Larsson SC, Orsini N. Red meat and processed meat consumption and all-cause mortality: a meta-analysis. Am J Epidemiol 2014;179:282-9. doi:10.1093/aje/kwt261

5 Bellavia A, Stilling F, Wolk A. High red meat intake and all-cause cardiovascular and cancer mortality: is the risk modified by fruit and vegetable intake?Am J Clin Nutr 2016;104:1137-43. doi:10.3945/ ajcn.116.135335

6 Kaluza J, Larsson SC, Linden A, Wolk A. Consumption of unprocessed and processed red meat and the risk of chronic obstructive pulmonary disease: a prospective cohort study of men. $\mathrm{Am}$ Epidemiol 2016:184:829-36. doi:10.1093/aje/kww101

7 Kaluza J, Akesson A, Wolk A. Processed and unprocessed red meat consumption and risk of heart failure: prospective study of men. Circ Heart Fail 2014;7:552-7. doi:10.1161/ CIRCHEARTFAILURE.113.000921

8 Lajous M, Bijon A, Fagherazzi G, Rossignol E, Boutron-Ruault MC, Clavel-Chapelon F. Processed and unprocessed red meat consumption and hypertension in women. Am / Clin Nutr 2014;100:948-52. doi:10.3945/ajcn.113.080598

9 O'Sullivan TA, Hafekost K, Mitrou F, Lawrence D. Food sources of saturated fat and the association with mortality: a meta-analysis. Am J Public Health 2013;103:e31-42. doi:10.2105/AJPH.2013.301492

10 Jeyakumar A, Dissabandara L, Gopalan V. A critical overview on the biological and molecular features of red and processed meat in colorectal carcinogenesis. J Gastroenterol 2017;52:407-18.

11 Daniel CR, Cross AJ, Koebnick C, Sinha R. Trends in meat consumption in the USA. Public Health Nutr 2011;14:575-83. doi:10.1017/ S1368980010002077

12 Agriculture USDoHaHSaUSDo. 2015-2020 Dietary Guidelines for Americans [Internet]. 8th ed. 2015 Dec 2016 [cited 2016 12/20]. https://health.gov/dietaryguidelines/2015/guidelines/chapter-2/acloser-look-at-current-intakes-and-recommended-shifts/.

13 Colditz GA, Manson JE, Hankinson SE. The Nurses' Health Study: 20-year contribution to the understanding of health among women. Womens Health 1997:6:49-62. doi:10.1089/jwh.1997.6.49

14 Rimm EB, Giovannucci EL, Willett WC, et al. Prospective study of alcohol consumption and risk of coronary disease in men. Lancet 1991:338:464-8. doi:10.1016/0140-6736(91)90542-W

15 Willett WC, Sampson L, Stampfer MJ, et al. Reproducibility and validity of a semiquantitative food frequency questionnaire. Am Epidemiol 1985;122:51-65. doi:10.1093/oxfordjournals.aje. a114086

16 Salvini S, Hunter DJ, Sampson L, et al. Food-based validation of a dietary questionnaire: the effects of week-to-week variation in food consumption. Int J Epidemiol 1989;18:858-67. doi:10.1093/ ije/18.4.858

17 Chiuve SE, Fung TT, Rimm EB, et al. Alternative dietary indices both strongly predict risk of chronic disease. / Nutr 2012;142:1009-18. doi:10.3945/jn.111.157222

18 Hu FB, Rimm E, Smith-Warner SA, et al. Reproducibility and validity of dietary patterns assessed with a food-frequency questionnaire. Am J Clin Nutr 1999;69:243-9. doi:10.1093/ajcn/69.2.243

19 Ley SH, Sun Q, Willett WC, et al. Associations between red meat intake and biomarkers of inflammation and glucose metabolism in women. Am J Clin Nutr 2014;99:352-60. doi:10.3945/ ajcn.113.075663

20 Rich-Edwards JW, Corsano KA, Stampfer MJ. Test of the National Death Index and Equifax Nationwide Death Search. Am J Epidemiol 1994;140:1016-9. doi:10.1093/oxfordjournals.aje. a117191

21 Rimm EB, Stampfer MJ, Colditz GA, Chute CG, Litin LB, Willett WC. Validity of self-reported waist and hip circumferences in men and women. Epidemiology 1990;1:466-73. doi:10.1097/00001648199011000-00009

22 Giovannucci E, Colditz G, Stampfer MJ, et al. The assessment of alcohol consumption by a simple self-administered questionnaire. Am J Epidemiol 1991;133:810-7. doi:10.1093/oxfordjournals.aje. a115960

23 Chasan-Taber S, Rimm EB, Stampfer MJ, et al. Reproducibility and validity of a self-administered physical activity questionnaire for male health professionals. Epidemiology 1996;7:81-6. doi:10.1097/00001648-199601000-00014

24 Bernstein AM, Sun Q, Hu FB, Stampfer MJ, Manson JE, Willett WC. Major dietary protein sources and risk of coronary heart disease in women. Circulation 2010;122:876-83. doi:10.1161/ CIRCULATIONAHA.109.915165

25 Physical Activity Guidelines Advisory Committee. Physical Activity Guidelines Advisory Committee Report, 2008. In: U.S. Department of Health and Human Services, editor. Washington, DC, 2008. https://health.gov/paguidelines/2008/report/pdf/ committeereport.pdf.

26 Abete I, Romaguera D, Vieira AR, Lopez de Munain A, Norat $T$. Association between total, processed, red and white meat consumption and all-cause, CVD and IHD mortality: a meta-analysis of cohort studies. Br / Nutr 2014:112:762-75. doi:10.1017/ S000711451400124X

27 Wang $X$, Lin X, Ouyang YY, et al. Red and processed meat consumption and mortality: dose-response meta-analysis of prospective cohort studies. Public Health Nutr 2016;19:893-905. doi:10.1017/S1368980015002062 
28 Nagao M, Iso H, Yamagishi K, Date C, Tamakoshi A. Meat consumption in relation to mortality from cardiovascular disease among Japanese men and women. Eur J Clin Nutr 2012;66:687-93. doi:10.1038/ejcn.2012.6

29 Pan A, Sun Q, Bernstein AM, et al. Red meat consumption and mortality: results from 2 prospective cohort studies. Arch Intern Med 2012;172:555-63. doi:10.1001/archinternmed.2011.2287

30 Pan A, Sun Q, Bernstein AM, Manson JE, Willett WC, Hu FB. Changes in red meat consumption and subsequent risk of type 2 diabetes mellitus: three cohorts of US men and women. JAMA Intern Med 2013;173:1328-35. doi:10.1001/ jamainternmed 2013.6633

31 Zhao Z, Li S, Liu G, et al. Body iron stores and heme-iron intake in relation to risk of type 2 diabetes: a systematic review and meta-analysis. PLoS One 2012;7:e41641. doi:10.1371/journal. pone.0041641

32 Bendinelli B, Palli D, Masala G, et al, InterAct Consortium. Association between dietary meat consumption and incident type 2 diabetes: the EPIC-InterAct study. Diabetologia 2013;56:47-59. doi:10.1007/ s00125-012-2718-7

33 Guasch-Ferré M, Satija A, Blondin SA, et al. Meta-analysis of randomized controlled trials of red meat consumption in comparison with various comparison diets on cardiovascular risk factors. Circulation 2019;139:1828-45. doi:10.1161/ CIRCULATIONAHA.118.035225

34 Susic D, Frohlich ED. Salt consumption and cardiovascular, renal, and hypertensive diseases: clinical and mechanistic aspects. Curr Opin Lipidol 2012;23:11-6. doi:10.1097/MOL.0b013e32834d9c52

35 Koeth RA, Wang Z, Levison BS, et al. Intestinal microbiota metabolism of L-carnitine, a nutrient in red meat, promotes atherosclerosis. Nat Med 2013;19:576-85. doi:10.1038/nm.3145

36 Tang WH, Wang Z, Levison BS, et al. Intestinal microbial metabolism of phosphatidylcholine and cardiovascular risk. N Engl/ Med 2013;368:1575-84. doi:10.1056/NEJMoa1109400

37 Etemadi A, Sinha R, Ward MH, et al. Mortality from different causes associated with meat, heme iron, nitrates, and nitrites in the
NIH-AARP Diet and Health Study: population based cohort study BMJ 2017;357:j1957. doi:10.1136/bmj.j1957

38 liang R, Camargo CAlr, Varraso R, Paik DC, Willett WC, Barr RG. Consumption of cured meats and prospective risk of chronic obstructive pulmonary disease in women. Am J Clin Nutr 2008:87:1002-8. doi:10.1093/ajcn/87.4.1002

39 Gillies GE, Pienaar IS, Vohra S, Qamhawi Z. Sex differences in Parkinson's disease. Front Neuroendocrinol 2014;35:370-84 doi:10.1016/i.yfrne.2014.02.002

40 Morris MC, Tangney CC, Wang Y, et al. MIND diet slows cognitive decline with aging. Alzheimers Dement 2015;11:1015-22. doi:10.1016/j.jalz.2015.04.011

41 Morris MC, Tangney CC. Dietary fat composition and dementia risk. Neurobiol Aging 2014;35(Suppl 2):S59-64. doi:10.1016/j. neurobiolaging.2014.03.038

42 Sääksjärvi K, Knekt P, Lundqvist A, et al. A cohort study on diet and the risk of Parkinson's disease: the role of food groups and diet quality. Br J Nutr 2013;109:329-37. doi:10.1017 S0007114512000955

43 Hellenbrand W, Boeing H, Robra BP, et al. Diet and Parkinson's disease. II: A possible role for the past intake of specific nutrients. Results from a self-administered food-frequency questionnaire in a case-control study. Neurology 1996;47:644-50. doi:10.1212/ WNL.47.3.644

44 Sinha R, Cross AJ, Graubard BI, Leitzmann MF, Schatzkin A. Meat intake and mortality: a prospective study of over half a million people. Arch Intern Med 2009;169:562-71. doi:10.1001/ archinternmed.2009.6

45 Rohrmann S, Overvad K, Bueno-de-Mesquita HB, et al. Meat consumption and mortality--results from the European Prospective Investigation into Cancer and Nutrition. BMC Med 2013;11:63. doi:10.1186/1741-7015-11-63

Supplementary information: additional figure and tables 1-7 